\title{
Representasi Masalah Sosial dalam Video Musik "Crazy" Simple Plan: Kajian Musik Pop dari Pendekatan Cultural Studies
}

\author{
${ }^{1}$ Lidya Kandowangko, ${ }^{2}$ Erwin Sianturi \\ ${ }^{1}$ Program Studi Sosiologi Agama IAKN Manado, ${ }^{2}$ Program Studi Pendidikan Musik Gereja \\ IAKN Manado \\ 11kandowangkolidya23@gmail.com, 2esianturi@iakn-manado.ac.id
}

\begin{abstract}
Abstrak
Budaya populer khususnya musik pop seringkali hanya dianggap sebagai bagian praktik kultural temporer dan bersifat komersil. Namun, musik pop dapat bermanifestasi sebagai media representasi masalah sosial untuk menampilkan kondisi pelik dalam masyarakat yang menikmati modernitas. Seperti video musik "Crazy" Simple Plan yang dikaji sebagai praktik representasi atas ragam masalah sosial dengan pendekatan cultural studies. Elaborasi antara kerangka konsep Giddens mengenai "juggernaut" dan konsep signifikansi dalam proses representasi khas cultural studies terhadap video musik "Crazy" Simple Plan. Penelitian terhadap praktik representasi dalam video musik menggunakan metode penelitian kualitatif dengan pendekatan semiotika. Penelitian ini menghasilkan representasi masalah sosial seperti kondisi tubuh dari operasi plastik, obesitas dan proses penuaan. Masalah remaja dan anak-anak di masa modern, serta ketimpangan sosial. Video musik pop menjadi media untuk memproduksi sistem simbolik yang mengkritik problema masyarakat yang tidak mampu mengendalikan "juggernaut" modernitas. Dengan demikian, musik pop tidak hanya dinilai dalam sudut pandang estetik, tetapi dapat menjadi bagian representasi simbolik dan media perlawanan yang futuristik. Sekaligus bermanfaat guna memberikan kesadaran sosial untuk beradaptasi dengan kondisi modernitas yang ambigu.
\end{abstract}

Kata Kunci: Musik pop, Video Musik, Representasi

\begin{abstract}
Popular culture, especially pop music, is often only considered as part of a temporary and commercial cultural practices. However, pop music can manifest as a medium of representation relate with social problems. Representation of social problems in music video to display the complicated conditions in a society that product of modernity. We analyzed the music video "Crazy" Simple Plan which is studied as a practice of representation of various social problems with cultural studies approach. Elaboration between Giddens' conceptual framework of "juggernaut" and the concept of significance in the process of representing a typical cultural studies of Simple Plan's "Crazy" music video. Research on the practice of representation in music videos used qualitative research methods with a semiotic approach. This research produces a representation of social problems such as the condition of the body from plastic surgery, obesity and the aging process. The problems of youth and children in modern times, as well as social inequality. Pop music videos have become a medium for producing a symbolic system that criticizes the problems of society which is not able to control the "juggernaut" of modernity. Thus, pop music is not only judged from an aesthetic point of view, but can be part of a symbolic representation and a futuristic medium of resistance. At the same time, it is useful to provide social awareness to adapt to the ambiguous conditions of modernity.
\end{abstract}

Keywords : Pop Music, Music Video, Representation 


\section{Pendahuluan}

Ragam selera masyarakat mengenai genre musik menghadirkan beragam jenis musik yang dikonsumsi dan direproduksi sebagai produksi kultural. Musik juga secara sadar masuk dalam konfigurasi budaya massa atau lebih dikenal dengan budaya pop (popular culture).

Terminologi budaya massa dan musik pop membawa kita pada pemikiran Theodor Adorno yang menyatakan pola musikal dan lirik dalam musik pop dieksploitasi guna kepentingan komersialisasi. Standarisasi yang bersifat temporer karna terus berganti, hanya didengar di waktu luang dan pendengarnya cenderung pasif. Namun, manifestasi musik pop bisa berfungsi secara sosialpsikologis guna menyesuaikan dengan kondisi fisik dan mekanisme kehidupan yang sedang berlangsung. ${ }^{1}$ Manifestasi tersebut bisa berdampak pada eksistensi musik pop sebagai media untuk merepresentasikan kondisi masyarakat yang sedang mengalami permasalahan melalui lirik, alunan nada, atau visualisasi video musik yang disajikan oleh para musisi.

Diperkuat dalam kajian sosiologi musik, dimana musik memiliki kekuatan sosial. Estetika dan aspek immaterial

1 Storey, John. 2006. Cultural Studies dan Kajian Budaya Pop. Yogyakarta: Jalasutra. yang dihasilkan dari repertoar dan sistem tonalitas memicu adanya interrelasi dengan tubuh, emosi, dan memori bersama. Ditambahkan dengan barisan lirik yang dimainkan dalam bermusik bisa berisi narasi yang mengungkap imajinasi sosial dan harapan adanya konsolidasi sosial. ${ }^{2}$ Narasi dalam lirik lagu tervisualisasi dalam video musik yang memiliki konfigurasi dan beragam fungsi disesuaikan dengan genre musik tertentu. Video Musik dihasilkan melalui proses recording, production, performance sehingga menjadi karya seni yang dihasilkan berdasarkan ekspresi kreativitas sang artis (musisi). Sekaligus menjadi narasi visual yang terkandung dalam beragam ilustrasi untuk menjelaskan makna dari lirik lagu yang dinyanyikan oleh musisi tersebut. ${ }^{3}$

Secara spesifik menelaah musik pop yang dihasilkan oleh komunitas musik punk, dimana konten lirik yang ditampilkan cenderung berkutat dengan perspektif anak muda terhadap masalah sosial yang dihadapi masyarakat. Komunitas Punk ataupun Skinhead atau sering disebut kaum kiri senantiasa dibingkai dalam representasi perlawanan terhadap alienasi struktur sosial dan sistem kelas

${ }^{2}$ DeNora, Tia. 2004. Music in Everyday Life. Cambridge: Cambridge University Press.

${ }^{3}$ Railton, Diane dan Paul Watson. 2011. Music Video and The Politics of Representation. Edinburgh: Edinburgh University Press. 
berdasarkan penampilan, gaya hidup ataupun musik. Ditekankan oleh Fiske yang menerjemahkan karya Laclau mengenai oposisi "populer" bahwa produksi kultural seperti musik populer bisa diberdayakan sebagai titik sentral perlawanan terhadap struktur dominasi yang dirasakan sebagai penindasan. ${ }^{4}$ Maka berkarya dalam musik merupakan salah satu bagian dari kritik sosial atas penindasan struktural ataupun kultural yang sering dialami oleh masyarakat modern.

Proses menghasilkan karya musik juga sebagai resistensi khas subkultur musik punk terhadap kondisi ketidakadilan sosial yang menimpa kelas pekerja dalam budaya kapitalis dan anak muda yang teralienasi dari budaya orang dewasa. ${ }^{5}$ Ditambah dengan kondisi masyarakat yang modern seakan menjebak setiap kelompok masyarakat yang sulit beradaptasi dengan modernisasi tersebut. Seperti visualisasi lirik dari video klip "Crazy" (dalam bahasa Indonesia berarti: Gila) dari grup band beraliran musik melodik punk asal Kanada yang bernama Simple Plan. Video musik yang mereka keluarkan adalah cara mereka untuk merepresentasikan maksud dari narasi

4 Fiske, John. 2011. Memahami Budaya Populer. Yogyakarta: Jalasutra.

5 Hogarty, Jean. 2017. Popular Music and Retro Culture in the Digital Era. New York: Routledge. teks lagu yang mereka susun. Untuk lebih jelasnya kami menyajikan lirik lagu "Crazy" dari band Simple Plan di bawah ini:

Tell me what's wrong with society When everywhere I look I see Young girls dying to be on TV They won't stop till they've reached their dreams

Diet pills, surgery

Photo shop pictures in magazines Telling them how they should be It doesn't make sense to me

Is everybody going crazy

Is anybody gonna save me

Can anybody tell me what's going on

Tell me what's going on

If you open your eyes

You'll see that something is wrong

I guess things aren't not how they used to be

There's no more normal families

Parents act like enemies

Making kids feel like it's World War 3

No one cares, no one's there

I guess we're all just too damn busy

And money's our first priority

It doesn't make sense to me

Is everybody going crazy

Is anybody gonna save me

Can anybody tell me what's going on

Tell me what's going on

If you open your eyes

You'll see that something is wrong

Is everybody going crazy

Is everybody going crazy

Tell me what's wrong with society

When everywhere I look I see

Rich guys driving big SUV's

When kids are starving in the streets

No one cares

No one likes to share

I guess lifes not fair

Is everybody going crazy

Is anybody gonna save me 
Can anybody tell me what's going on Tell me what's going on

If you open your eyes

You'll see that something, something is wrong

Is everybody going crazy

Is anybody gonna save me

Can anybody tell me what's going on

Tell me what's going on

If you open your eyes

You'll see that something, something is wrong ${ }^{6}$

Memberikan judul "Crazy" atau "Gila" menggambarkan suatu keadaan yang penuh tanda tanya, dilihat dari narasi teksnya serta bagaimana lirik lagu tersebut menekankan apakah orang-orang di dunia ini sudah gila, serta berbagai kata-kata kritik terhadap kegiatan masyarakat modern yang bertransformasi ke dalam standar hidup yang penuh ambiguitas. Diperkuat dengan video musik yang berisi visualisasi ilustrasi yang menajamkan makna dari lirik lagu sebagai karya seni yang kreatif dan kritis mengenai kondisi masyarakat saat ini.

Tulisan kami pun lebih menitikberatkan pada narasi visual dalam video musik yang berisi representasi masalah sosial sebagai bagian konsekuensi modernitas. Kerangka teoritis yang kami gunakan untuk menganalisis permasalahan sosial yang digambarkan lewat video

\footnotetext{
${ }^{6}$ Lirik lagu "Crazy" - Simple Plan diakses dari https://lirik.kapanlagi.com/artis/simpleplan/crazy/. pada tanggal 1 Oktober 2020.
}

klip Crazy - Simple Plan mengacu pada pemikiran Giddens mengenai "juggernaut" (panser raksasa). Menurut Giddens "modernitas dalam bentuk panser raksasa ini sangat dinamis. Kehidupan modern adalah sebuah "dunia yang tak terkendali" (runaway world) dengan langkah cakupan, dan kedalaman perubahannya yang jauh lebih besar dibandingkan dengan sistem sebelumnya. ${ }^{7}$

Secara bersamaan konsep kunci Cultural Studies atau studi kebudayaan yang menekankan pada praktik signifikansi representasi juga menjadi pisau analisis dalam membedah video musik pop dari lagu "Crazy" Simple Plan. Proses signifikansi adalah bagaimana alur pemaknaan sosial dibangun melalui tanda-tanda atau simbol-simbol kultural yang dihadirkan dalam visualisasi video musik. Dielaborasi dengan praktik representasi yang menelaah bagaimana makna diproduksi, ditampilkan dan digunakan dalam ragam konteks sosial tertentu. ${ }^{8}$

Maksud tulisan kami mengantarkan pada manfaat teoritis dalam pengembangan kajian musik pop dengan pendekatan cultural studies. Secara praktis, bisa

7 Ritzer, George. 2007. Teori Sosiologi Modern. Jakarta: Kencana.

${ }^{8}$ Barker, Chris. 2000. Cultural Studies, Theory and Practice. London: Sage Publications. 
berkontribusi pada kreatifitas para musisi untuk memberdayakan musik pop sebagai modal kapital dalam kritik sosial dan media resistensi terhadap ketidakadilan tanpa konflik berbasis kekerasan.

Dengan alur analisis berdasarkan rumusan masalah yang pertama bagaimana para aktor yang terkena dampak dalam permasalahan modernitas direpresentasi dalam musik video ini? Kedua, bagaimana praktik signifikansi terhadap masalah sosial dari masyarakat modern yang direpresentasikan dalam video musik?

\section{Metode Penelitian}

Dalam kajian mengenai representasi sosial dalam video musik pop "Crazy" Simple Plan, kami menggunakan metode penelitian kualitatif dengan pendekatan analisis semiotika. Analisis kami menekankan pada ilmu tanda yaitu suatu hal yang merepresentasikan suatu hal yang dipikirkan atau dipahami seperti kode, bilangan, musik atau ekpresi tertentu. ${ }^{9}$ Lokus penelitian kami berdasarkan keseluruhan konten yang divisualisasikan dalam video musik "Crazy" Simple Plan, namun fokus

\footnotetext{
${ }^{9}$ Manning, Peter $\mathrm{K}$ dan Betsy Cullum-Swan, 2009. Analisis Naratif, Analisis Konten, dan Analisis Semiotika, dalam Norman K. Denzin dan Yvonna S. Lincoln (Eds) Handbook of Qualitative Research, Yogyakarta: Pustaka Pelajar.
}

analisis kami yaitu bagian scene yang menampilkan representasi masalah sosial. Dalam analisis semiotika tidak melakukan teknik sampling yang melibatkan responden atau informan tetapi kami melibatkan ragam tanda berkaitan dengan representasi masalah sosial yang diperoleh dalam setiap potongan scene di video musik yang sekaligus menjadi sumber data primer. Beragam literatur terkait dengan pendekatan cultural studies dan musik popular dijadikan sebagai sumber data sekunder dalam penelitian ini. Selanjutnya, analisis data dilakukan dengan mengambil potongan video, setelah itu setiap objek dianalisis dalam proses signifikansi atas setiap bagian video klip yang merepresentasikan masalah sosial guna mendapatkan dapat yang valid dan reliabel.

\section{Hasil dan Pembahasan}

Kemajuan era modern dengan berbagai perubahannya membawa kita pada efesiensi dan efektivitas ternyata memiliki makna destruktif bagi mereka yang tak mampu mengendalikannya. Era Modern ditandai adanya modernitas sebagai atribut yang dipakai oleh orang-orang modern. Masyarakat modern diperhadapkan dengan berbagai hiburan sekaligus ratapan duka. 


\begin{tabular}{llr}
\multicolumn{2}{c}{ Menciptakan kontradiksi bagi } \\
masyarakat modern, & karena \\
modernitas & memicu & hadirnya
\end{tabular}
persaingan dan permasalahan yang lain. Masyarakat modern menjadikan uang sebagai prioritas, objek yang memiliki daya pesona bagi masyarakat modern, karena hampir setiap hal di dunia modern dapat kita tukarkan dengan uang. Selain itu berbagai masalah lain timbul dalam kehidupan masyarakat modern dengan tidak memperdulikan perbedaan gender, usia, status sosial, pekerjaan maupun agama.

\section{Permasalahan} modernitas digambarkan dalam berbagai hal yang menimpa para actor, dimana secara gamblang direpresentasikan dalam video musik "Crazy" Simple Plan. Kemajuan modern membuat mereka dipicu untuk melakukan berbagi hal agar dapat menyesuaikan dengan situasi dan kondisi sosial. Namun, disisi lain ternyata hal itu menciptakan berbagai macam masalah.

\section{Representasi Permasalahan Para}

\section{Aktor sebagai Konsekuensi}

\section{Modernitas}

Video musik "Crazy" Simple Plan menampilkan ragam representasi masalah sosial yang dialami oleh para aktor sebagai konsekuensi modernitas. Mulai dari ketidaknyamanan terhadap bentuk tubuh karena standarisasi kecantikan atau bentuk tubuh ideal. Berakibat pada banyaknya orang yang melakukan modifikasi pada bentuk yang tidak di-inginkan agar sesuai dengan standar yang diagungkan oleh masyarakat. Meskipun standar yang ada cenderung berkiblat pada standar dan trend dari perusahaan kecantikan dengan tujuan mendapatkan keuntungan.

Seperti yang digambarkan dalam potongan video klip di bawah ini :

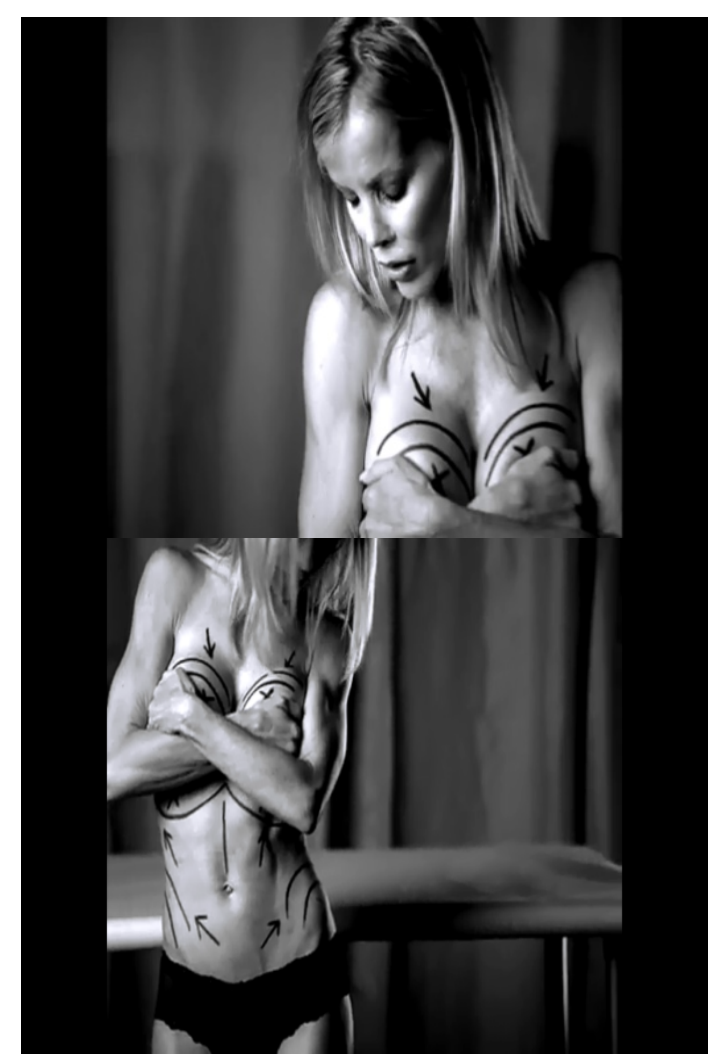

Gambar 1. Perempuan Merefleksikan Kesempurnaan (bagian video klip "Crazy" Simple Plan. 2020)

Mungkin hanya sedikit orang yang tahu salah satu tahap dalam melakukan operasi plastik (plastic 
surgery) yang banyak dilakukan oleh sebagian besar perempuan untuk memaksimalkan penampilan. Operasi plastik biasanya dilakukan untuk memperbaiki bagian-bagian tubuh tertentu yang mengalami cacat. Namun, dengan perkembangan teknologi dan kewajiban tersirat bilamana perempuan harus tampil sempurna.

Perempuan memang cenderung terjebak dalam stereotip kecantikan dalam tubuh langsing. Dalam studi budaya menggambarkan bagaimana kepemilikan tubuh yang langsing merupakan kondisi ideal dan meningkatkan daya tarik bagi perempuan. Implikasinya banyak perempuan yang menderita anoreksia dan bulimia karena selalu dipaksa untuk memiliki tubuh langsing. ${ }^{10}$

Cara instan pun dilakukan seperti memilih melakukan operasi plastik pada beberapa bagian tubuh untuk kecantikan yang sempurna. Di gambar I menunjukkan tahap sang perempuan telah menentukan tempat untuk melakukan permak tubuh. Persaingan penampilan bagi para perempuan di era modern saat ini memaksa perempuan terus tertekan dengan memaksimalkan tubuh memakai cara apapun.
Secara kontradiktif, persoalan tubuh tidak hanya bergulat dengan bentuk badan ideal. Karena gaya hidup instan dan pola makan yang tidak sehat mengakibatkan persoalan obesitas bagi masyarakat modern. Didukung juga oleh simplifikasi waktu maka konsumsi makanan cepat saji lebih digemari walaupun memiliki kandungan yang tidak baik bagi Kesehatan. Dalam video musik direpresentasikan bagaimana keluarga yang anggotanya memiliki obesitas atau kelebihan berat badan. Seperti pada gambar 2 di bawah ini:
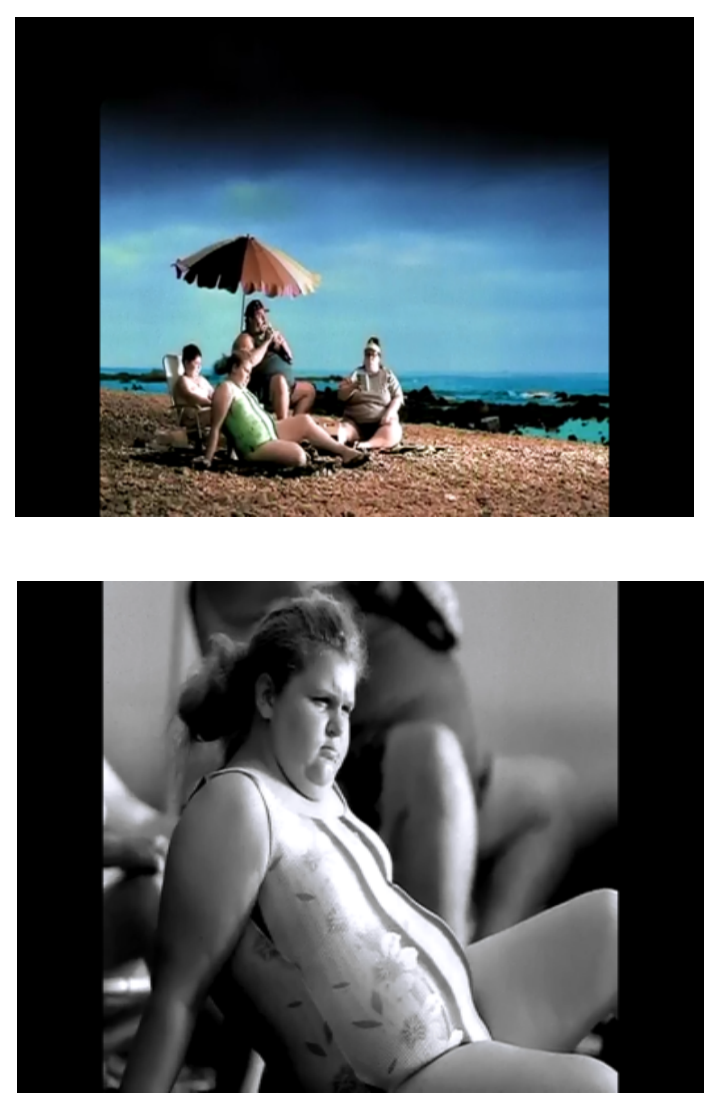

${ }^{10}$ Barker, 2000, op cit 


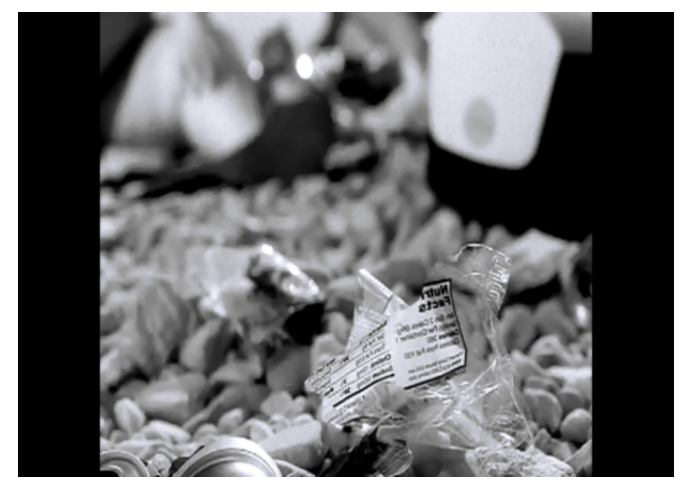

Gambar 2. Keluarga Obesitas dan penjelasan kandungan kalori dalam bungkus makanan (bagian video klip "Crazy" Simple Plan. 2020)

Era modern yang mengharuskan setiap orang untuk menghargai waktu menyebabkan terciptanya berbagai objek konsumsi yang instan. Sebagian besar berdampak pada makanan, atau dikenal dengan makanan cepat saji (fast food). Karena lebih mementingkan efisiensi waktu maka kesehatan menjadi terabaikan. Akibatnya adalah kegemukan seperti di gambar 2 keluarga dengan tubuh gemuk sedang bersantai menikmati makanan. Di gambar bagian bawah digambarkan catatan kandungan kalori yang terkandung pada makanan. Orangorang modern sebagian besar memakan makanan yang berkalori tinggi, maka kegemukan sering menjadi masalah pada masyarakat modern.

Selain itu penurunan produktivitas tubuh menjadi hal yang menakutkan bagi masyarakat modern. Seperti pada gambar 3 di bawah ini:
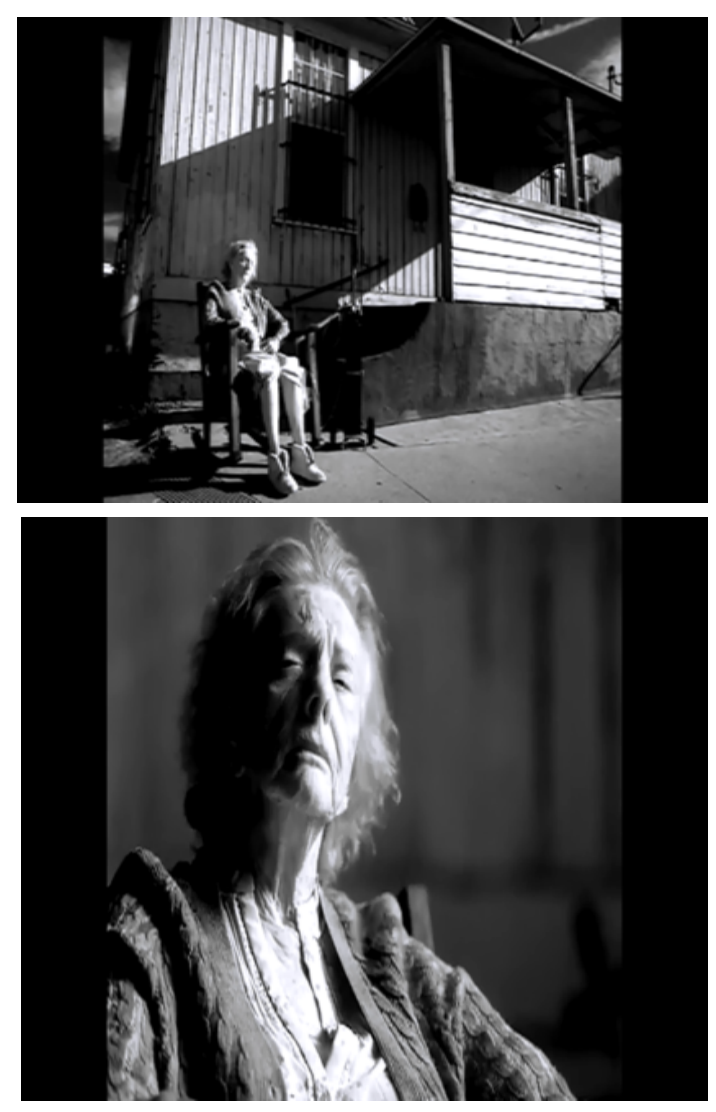

Gambar 3. Nenek Duduk Di Kursi Goyang. (bagian video klip "Crazy" Simple Plan. 2020)

Bila sudah dipengaruhi oleh penurunan kondisi tubuh bukan saja karena penyakit, tetapi termakan usia. Problema ini sering dialami oleh kelompok yang berusia lanjut (lansia). Apalagi memiliki anak dengan rutinitas yang tinggi mengakibatkan banyak dari mereka yang menitipkan orang tuanya ke panti werda atau panti jompo.

Nenek yang sudah lanjut usia telah kehilangan produktivitas. Banyak manula yang merasa kesendirian dan terabaikan. Kasih sayang antara anak dan orang tua telah digerus oleh kewajiban kerja dan nilai-nilai materi. Kursi goyang lebih 
menekankan keberadaan mereka yang sudah tidak dapat melakukan kegiatan yang produktif.

Kompleksitas yang lain adalah permasalahan remaja. Sebenarnya fenomena ini bukan hal yang baru, namun terus saja menarik dikaji karena terus nampak apalagi di kehidupan masyarakat modern. Video musik "Crazy" Simple Plan memberikan porsi yang cukup banyak saat merepresentasi permasalahan remaja. Seperti di gambar 4:
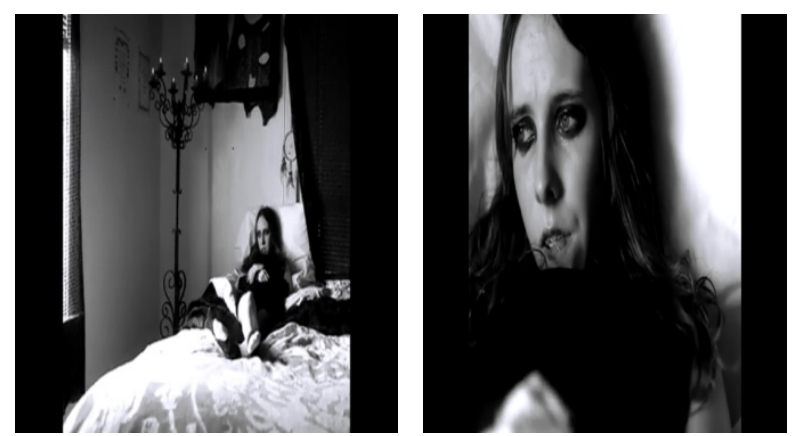

Gambar 4: Seorang remaja dengan tatapan kosong (bagian video klip "Crazy" Simple Plan. 2020)

Pada gambar 4 bagian atas, menunjukkan seorang remaja berpakaian gothic berada di kamarnya sambil menangis. Tangisan memang tidak selalu menandakan kesedihan, tetapi dilihat dari sorotan mata menandakan remaja yang bimbang. Disisi lain, remaja harus diperhadapkan dengan masalah kehidupan yang pelik dan mereka membutuhkan media penyaluran agar tidak terjebak pada kondisi psikis yang lebih parah. Di bawah ini adalah gambar 5 yang merepresentasikan berbagai cara yang dilakukan remaja untuk meluapkan kesedihannya.
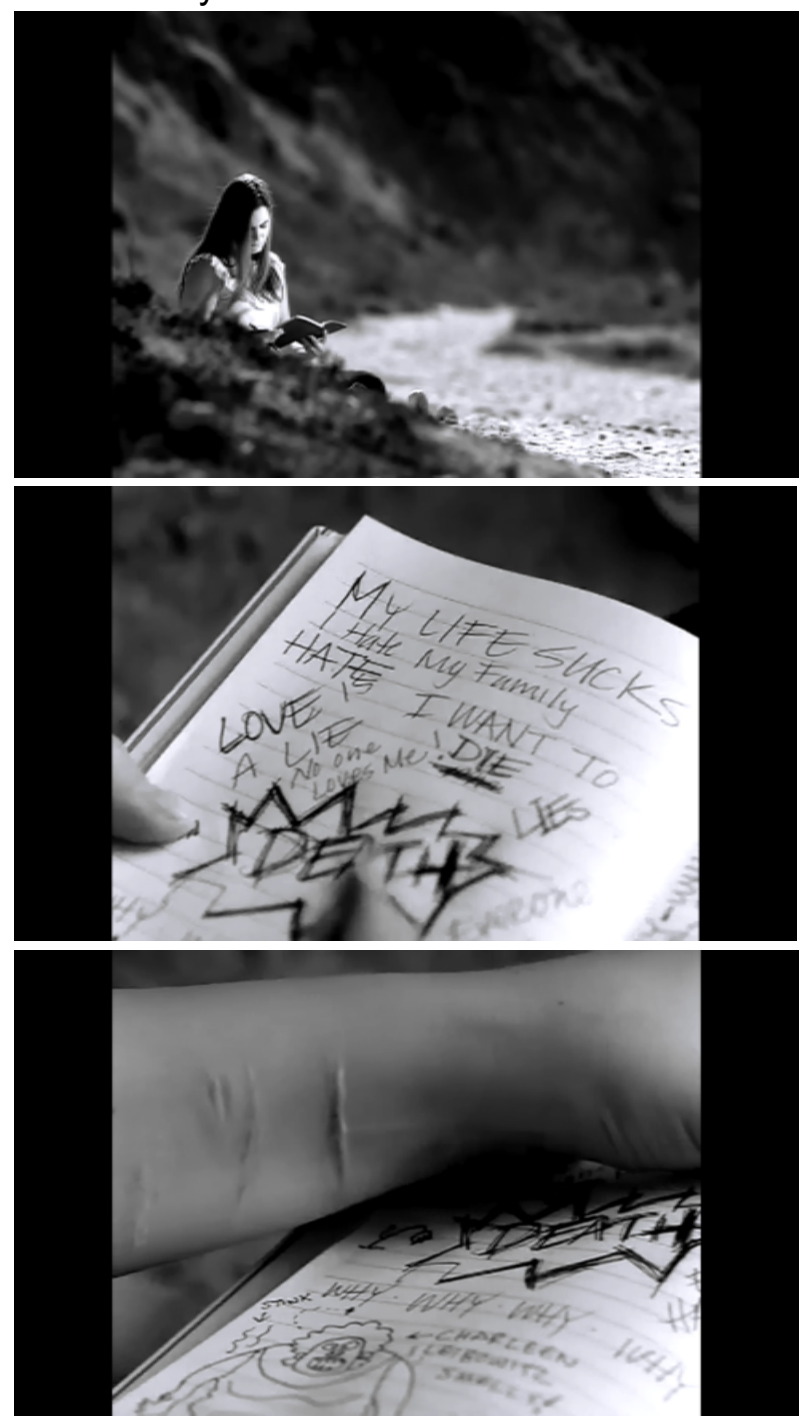

Gambar 5: Cara Remaja Meluapkan Emosi (bagian video klip "Crazy" Simple Plan. 2020)

Gambar 5 memperlihatkan bagaimana representasi masalah seorang remaja yang depresi sedang melampiaskan amarahnya. Terdapat 2 (dua) sarana yang dia gunakan untuk melampiaskan masalahnya, yaitu dengan mencoret buku harian dan menyayat bagian tubuh sebagai pelampiasan kekesalan. 
Para remaja yang berada pada masa transisi, dimana mereka membutuhkan perhatian orang tua merasa terabaikan dan merasakan depresi. Era modern pun, selalu menawarkan banyak pilihan untuk melupakan masalah hidup. Tetapi, jalan keluar remaja sering didominasi oleh perbuatan negatif, seperti mabukmabukkan, narkoba (Narkotik dan Obat Terlarang), seks bebas dan sebagainya.

Tidak bisa disangkal berbagai latar belakang menyebabkan rumitnya permasalah remaja. Keluarga yang sibuk dengan tuntutan pekerjaan, terlebih lagi sudah dikaitkan dengan kebutuhan akan uang yang sangat terasa bagi masyarakat modern. Hal itu berdampak pada para orang tua diharuskan bekerja keras agar mendapatkan uang yang cukup memenuhi kebutuhan tak terbatas. Terdapat pula penggambaran remaja yang bermasalah disebabkan perceraian orang tua. Problematika bagi remaja semakin memuncak khususnya diwaktu masa menjelang perceraian dimana remaja harus menyaksikan konflik diantara kedua orang tua.

Masalah keluarga modern tidak hanya berdampak pada kalangan remaja. Tetapi juga anak-anak. Dalam video musik "Crazy" menyajikan representasi masalah sosial yang dihadapi anak-anak masa kini yang menjadikan siaran televisi sebagai media belajar dan cenderung melakukan kegiatan imitatif. Artinya, seorang anak mengikuti semua aktivitas yang dia lihat di televisi. Secara lebih jelas diperlihatkan pada gambar 6 di bawah ini:

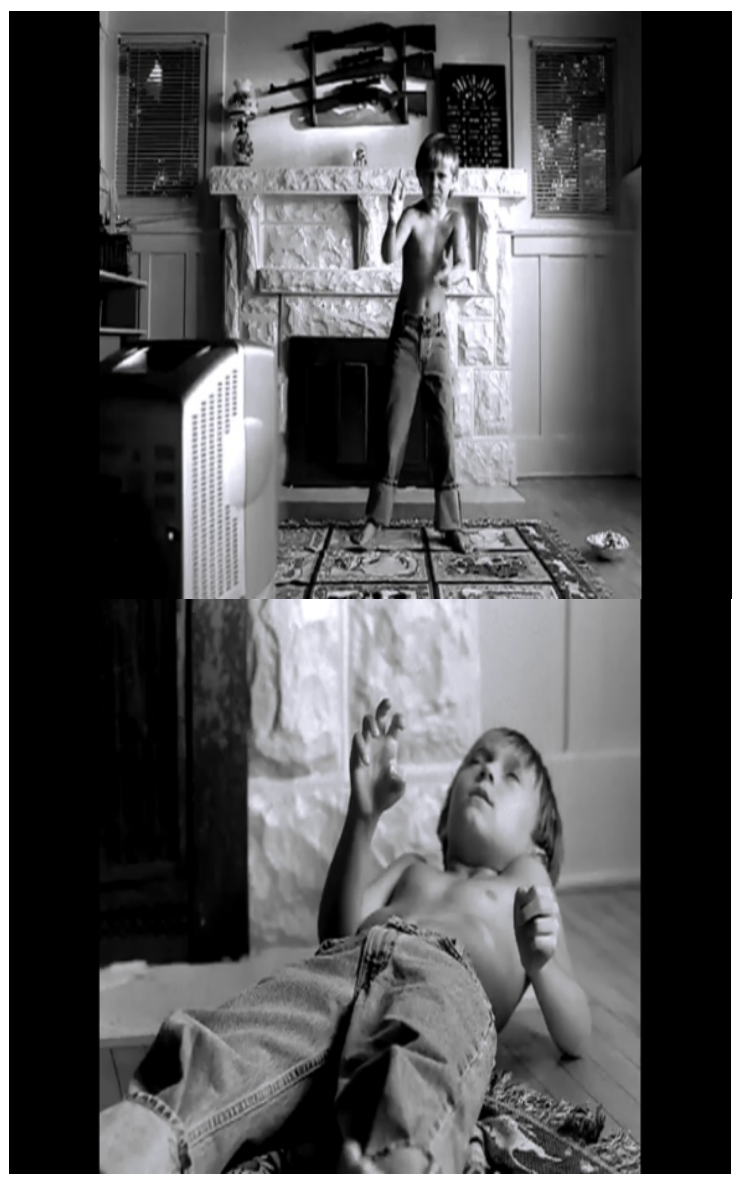

Gambar 6. Anak Menonton dan Meniru Tontonan Televisi (bagian video klip "Crazy" Simple Plan. 2020)

Oleh karena itu, orang tua selalu diingatkan untuk terus mengawasi anakanaknya dalam memilih tontonan televisi. Kita dapat melihat bagaimana si anak menonton sambil meniru semua gaya yang ada di televisi tanpa kemampuan menyaring mana yang baik atau buruk. Tumbuh kembang anak pun menjadi terganggu atau akan mengarah ke perilaku negatif apabila selalu menonton 
acara TV yang tidak sesuai dengan umur atau tidak mendidik.

Representasi masalah sosial yang lain terdapat pada bagian terakhir video music "Crazy" Simple Plan yaitu masalah kesenjangan sosial. Fenomena ini dapat terjadi karena aksesibilitas terhadap sumber daya baik material ataupun nonmaterial bersifat timpang. Perbedaan kelas sosial bisa disebabkan karena disparitas sosial berdasarkan pendapatan, pekerjaan dan gaya hidup. Pada gambar 7 menunjukkan potret kesenjangan sosial antara si kaya dan si miskin.
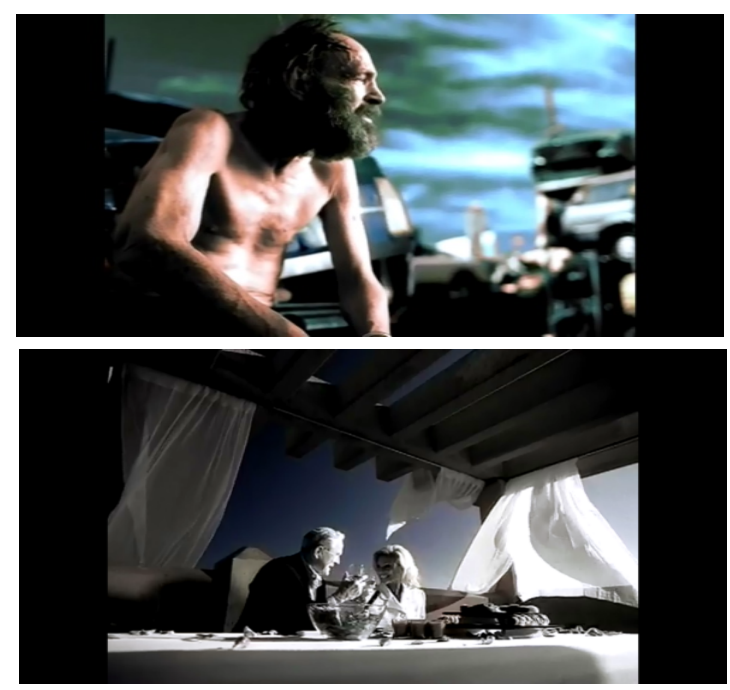

Gambar 7: Kesenjangan Sosial antara Si Kaya dan Si Miskin) (bagian video klip "Crazy" Simple Plan. 2020)

Kesenjangan sosial memang menjadi permasalahan klasik disaat berbicara mengenai permasalahan sosial. Gambar 7 memperlihatkan pesta kaum kaya atau kelas atas dengan perbandingan keberadaan kaum miskin. Gambaran yang penuh kontradiksi dan ironi. Simbol wine (minuman yang bernilai mahal dan berkelas) yang dipegang oleh pasangan di bagian bawah bertolak belakang dengan kondisi seorang pria yang bertelanjang dada di bagian atas. Ketimpangan sosial memang menjadi momok yang terus dihadapi oleh masyarakat baik di negara maju maupun negara berkembang.

\section{Praktik Signifikansi terhadap Kondisi “Juggernaut" dalam Video Musik}

Mengapa orang-orang yang berada pada video musik tersebut mengalami berbagai permasalahan. Menurut Giddens, kita yang sedang menikmati produk modernitas harus punya keterampilan dalam mengendalikan "juggernaut" guna meminimalisasi bahaya dan memaksimalkan peluang. ${ }^{11}$

Dikarenakan mereka yang tidak dapat mengendalikan modernitas mereka akan terlindas dengan "juggernaut" dalam bentuk masalah sosial. Lebih ditekankan bahwa individu dalam masyarakat modern kalah saing kekuasaannya dengan mekanisme modern.

Dimulai dari tubuh perempuan merefleksikan suatu rendahnya kekuasaan akan tubuh karena mencari kesempurnaan dengan operasi plastik akibat tuntutan masyarakat. Kegemukan yang menjadi masalah dari masyarakat

11 Giddens, Anthony. 2011. KonsekuensiKonsekuensi Modernitas. Yogyakarta: Kreasi Wacana. 
modern karena selain makanan cepat saji, terdapat pula kebiasaan yang direproduksi karena teknologi, seperti banyak orang malas berolahraga karena lebih banyak menghabiskan waktu di depan komputer. Karena itu berakibat pada minimnya proses pembakaran lemak yang menyebabkan obesitas.

Selain itu, produktivitas dan kualitas kerja sangat dibutuhkan pada masyarakat modern. Maka kita melihat bagaimana ketidakberdayaan sang nenek dalam kesendirian dan terabaikan.

Kondisi para remaja lebih ekstrim karena tingginya tingkat depresi, dimana melukai diri sering menjadi jalan keluar, tetapi menulis catatan harian serta menghabiskan waktu di kamar masih dilakukan oleh sebagian besar remaja. Anak-anak juga menjadi titik perhatian karena menentukan tontonan bagi anakanak membutuhkan pengawasan orang tua.

$$
\text { Penutupnya adalah kondisi }
$$
kesenjangan sosial yang tetap menjadi masalah dalam masyarakat modern. Demikianlah alur proses signifikansi yang disajikan oleh video music "crazy" simple plan. Analisis terhadap pola representasi yang kami lakukan menemukan bagaimana produk pemaknaan atas sistem simbolik yang dapat dikonstruksi berdasarkan kondisi sosial masyarakat modern.

\section{Kesimpulan}

Berdasarkan telaah atas praktik signifikansi yang kami lakukan dapat memberikan gambaran bagaimana video musik bukan saja sebagai karya seni yang bernilai estetik, tetapi sebagai bagian dari produksi kultural populer yang menyajikan model kritik sosial yang futuristik. Video musik pop secara nyata mengkonfigurasikan ragam representasi pengalaman masyarakat modern cenderung pada keprihatinan, kondisi tidak bahagia, pengabaian sosial dan ketimpangan sosial. Namun, musik pop bisa memiliki nilai bagi anak muda yang mencari wadah untuk mewakili identitas subkultur mereka yang cenderung menampilkan perlawanan.

Selain itu, sistem simbolik dalam video musik "Crazy" Simple Plan bisa menjadi penanda bahwa masyarakat modern harus bisa memiliki kemampuan adaptasi agar tidak terlindas dengan "juggernaut". Nilai dan moralitas yang ada berkelindan dengan tuntutan kompetisi gaya hidup masyarakat, seharusnya bisa saling menegosiasi agar timbulnya keseimbangan diantara keduanya meski kompleks.

\section{Kepustakaan}

Barker, Chris. 2000. Cultural Studies, Theory and Practice. London: Sage Publications. 
DeNora, Tia. 2004. Music in Everyday Life. Cambridge: Cambridge University Press.

Fiske, John. 2011. Memahami Budaya Populer. Yogyakarta: Jalasutra.

Giddens, Anthony 2011, KonsekuensiKonsekuensi Modernitas, Yogyakarta: Kreasi Wacana.

Hogarty, Jean. 2017. Popular Music and Retro Culture in the Digital Era. New York: Routledge

Lirik lagu "Crazy" - Simple Plan diakses dari https://lirik.kapanlagi.com/artis/simpl e-plan/crazy/. pada tanggal 1 Oktober 2020.

Manning, Peter K dan Betsy CullumSwan, 2009. Analisis Naratif, Analisis Konten, dan Analisis Semiotika, dalam Norman K. Denzin dan Yvonna S. Lincoln (Eds) Handbook of Qualitative Research, Yogyakarta: Pustaka Pelajar.

Railton, Diane dan Paul Watson. 2011. Music Video and The Politics of Representation. Edinburgh: Edinburgh University Press.

Ritzer, George. 2007. Teori Sosiologi Modern. Jakarta: Kencana.

Storey, John. 2006. Cultural Studies dan Kajian Budaya Pop. Yogyakarta: Jalasutra. 